\title{
CONSIDERACIONES SOBRE LA DANZA Y LOS
}

METADISCURSOS ARTÍSTICOS

Magdalena Casanova

Universidad Nacional de Artes

DOI: $10.36446 /$ be.2019.47.94

\section{Resumen}

Este trabajo se interroga acerca de la persistencia en la actualidad de lo que Jean-Marie Schaeffer ha denominado "teoría especulativa del Arte" en el discurso actual sobre la danza. Discute las tesis de algunos de los principales trabajos reunidos en el volumen colectivo La danza y la palabra (Caracas, 2005) y recupera, para el análisis conceptual de las artes del movimiento, el importante debate mantenido en 1982 entre Monroe Beardsley, por un lado, y Sally Banes y Noël Carroll, por el otro.

\section{Palabras clave}

Danza moderna - Teoría especulativa del Arte - Esencialismo - Artes del movimiento

\section{Considerations about dance and artistic metadiscourses}

\section{Abstract}

This paper inquiries about the persistence of what Jean-Marie Schaeffer has called "speculative theory of Art" in the current discourse on dance. It discusses the theses of some of the main works gathered in the collective volume La danza y la palabra (Caracas, 2005) and recovers, for the conceptual analysis of the arts of the movement, the important debate held in 1982 between Monroe Beardsley, on the one hand, and Sally Banes and Noël Carroll, on the other.

\section{Keywords}

Arts of movement - Speculative theory of Art - Essentialism - Arts of movement

Recibido: 11/04/2017. Aprobado: 22/08/2018. 
Los discursos sobre las artes -y en particular sobre las artes del movimiento- están poblados de frases hechas. La danza, suele decirse, "permite viajar hacia las profundidades del ser", provoca "climas espirituales", posibilita "escuchar resonancias que vienen del origen", o permite la "comunión con el verbo originario". Estas expresiones que se perciben como naturales merecen, sin embargo, ser examinadas en sus fundamentos, ya que presuponen no solo un modo de entender la danza, sino también el arte en general.

Partiendo de la hipótesis según la cual toda teoría del arte entraña, al mismo tiempo, una manera de entender el discurso sobre las artes, en las siguientes páginas me propongo, en primer lugar, trazar una breve revisión de la concepción de la danza (y de la experiencia estética que se involucra en este lenguaje artístico) plasmada en algunos metadiscursos contemporáneos para indagar, en un segundo momento, en la relación que estos metadiscursos mantienen con la crítica.

\section{LA TRADICIÓN ESPECULATIVA}

Jean-Marie Schaeffer (2012: 20) ha mostrado que el romanticismo sacraliza el arte "como compensación de una realidad desfalleciente". La imposibilidad de acceder a lo absoluto a través de la filosofía, la confianza en la imaginación humana, la importancia de la experiencia estética y su relación con la belleza, se convierten en argumentos que exaltan el arte hasta volverlo una forma de revelación de la verdad. La "revolución romántica" encarna, de este modo, la "respuesta a una doble crisis espiritual: la de los fundamentos religiosos de la realidad humana y la de los fundamentos trascendentes de la filosofía" (24).

Esta "teoría especulativa de Arte", señala Schaffer, persiste aún hoy y tiene importantes consecuencias tanto para el arte como para sus metadiscursos. El arte cumple, por un lado, una función de "revelación ontológica" y, por el otro, se determina correlativamente como un "saber extático, es decir, que revela verdades trascendentes, inaccesibles a las actividades cognitivas profanas" (24). Esta tesis descansa sobre un dualismo metafísico, según el cual existiría una realidad aparente, captable a través de los sentidos y el intelecto, y una realidad (que aquí llamamos realidad verdadera) alcanzable solamente a través del arte. Los efectos de esta concepción se trasladan a los metadiscursos artísticos que en adelante tendrían que "proporcionar una legitimación filosófica de la función extática del arte, mostrando que su esencia reside en su función de revelación ontológica" (23). El arte debe, por lo tanto, legitimarse filosóficamente, ya que su concepto sería, en última instancia, subsidiario de esta práctica.

Veamos las principales características de esta "teoría especulativa del Arte" con el fin de preguntarnos, a continuación, si ella persiste en el discurso actual sobre la danza y qué efectos tiene. En primer lugar, Schaeffer afirma que, durante el romanticismo, la desazón causada por la ausencia de valores y respuestas definitivas a cuestiones existenciales produjo una gran desorientación espiritual que desembocó en la búsqueda urgente de una recuperación de la unidad armoniosa del hombre. Esta unidad no 
era pensada como un principio abstracto, sino como una "fuerza viviente y vivificante, alma de un universo orgánico en el que todo es vida" (24). En segundo término, esta desarmonía se percibió como la pérdida de conexión con lo Absoluto, con el fundamento de lo real (el Ser o el Dios de una "metafísica dogmática" desbaratada por el criticismo kantiano). De esta manera, como la filosofía ya no puede alcanzar este conocimiento, en vez de renunciar a esta "ontoteología", el romanticismo otorga al arte la gran tarea de producir una "intuición intelectual de lo absoluto" (26).

Ahora bien, según Schaeffer, la instauración del Arte -con mayúscula- como revelación ontológica "no nace simplemente de un desfallecimiento de la filosofía como tal sino, de manera más específica, de la incompatibilidad entre su forma discursiva y su contenido (o su referencia) ontológico(a)" (27). Dicho de otro modo, en virtud de su heterogeneidad, la forma discursiva eminentemente filosófica es incapaz de enunciar su propio contenido. Este contenido se convierte, entonces, en lo que el arte debe expresar/enunciar/representar, de modo que la "teoría especulativa del Arte" desemboca en una doctrina esencialista del arte, cuya supervivencia hasta nuestros días se traduce en asignar al arte una función compensatoria de las diversas figuras del desencantamiento, prometiendo el acceso a una vida "supuestamente 'auténtica'” (30-31).

La persistencia de esta concepción metafísica, sostiene Schaeffer, se explica no solo por un desconocimiento del funcionamiento del arte, sino también por la ausencia de criterios de evaluación. $\mathrm{Al}$ hacer del arte un medio de revelación de la verdad, la "teoría especulativa del Arte" requiere, lógicamente, que el criterio de evaluación dependa del grado de cumplimiento de este cometido supremo: "si el arte revela el ser, las obras artísticas mismas revelan el arte y deben descifrarse como tales, es decir, como realizaciones empíricas de una misma esencia ideal" (39). De esta manera, el ideal artístico se construye a partir de un criterio de exclusión que presenta una definición evaluativa como descriptiva. En consecuencia, la función del crítico se limita a colaborar en el desciframiento de la obra o a argumentar si esta pertenece o no al "mundo del arte" según los criterios previamente establecidos por la teoría, lo cual va en desmedro de "una descripción analítica de los hechos artísticos" y de otras posibles experiencias estéticas (43). La obra de arte, concluye Schaeffer, no posee ninguna esencia interna; es un objeto intencional que, en todo caso, se define en la relación que establece con el espectador: "es y llega a ser lo que los hombres lo hacen ser y llegar a ser" (43).

\section{LA DANZA COMO “VIDA EN LA VIDA"}

La danza es un lenguaje que posee una materialidad efímera y transitoria. Su relación directa con la temporalidad generó no pocas dificultades a lo largo de la historia de la estética. El vínculo con las palabras, por otra parte, fue no solo conflictivo, sino muchas veces considerado como inadmisible tanto por coreógrafos como por teóricos. De hecho, no resulta sencillo encontrar textos que tematicen conjuntamente ambas áreas. Una excepción en el campo de nuestra lengua es el libro La danza y la palabra (2005), editado por el Instituto Universitario de Danza de Caracas. El volumen se compone de siete ensayos escritos a partir de un curso titulado "Las fronteras del cuerpo", a cargo de Sonia Sanoja, en el que se trató la conexión fundamental entre danza y literatura. 
Esta obra resulta particularmente relevante porque aborda el tópico puntual del vínculo entre los dos tipos de lenguajes. Ya desde la presentación, Sanoja llama la atención sobre un modo de pensar la danza (y en función de ello, la escritura) que genera algunas sospechas sobre una visión que repite una lógica ya conocida: se habla, como adelantamos al inicio del trabajo, de la creación de un "clima espiritual", de viajes "hacia las profundidades de su ser", de escuchar resonancias que "vienen del origen", de "la vivencia del cuerpo iluminado en comunión con el verbo originario" (Paolillo 2005: 7-8).

Este tipo de pensamiento sobre las artes del movimiento se mantiene en casi todos los ensayos. Gordils se refiere a la esencia eterna de la obra de arte que debe ser leída apropiadamente para superar las "fronteras del cuerpo" (24-25). Pérez-Wilke se ocupa de la "dimensión metafísica de la danza", de su relación con lo sagrado y de su capacidad de develar algo superior (32-34). Quintero considera la danza, siguiendo a Paul Valéry, como el lugar de la "expresión espiritual humana", como expresión del alma y como espacio de "lo innombrado", y al espectador como un "participante silencioso" (49-51). Rappa se refiere a la danza como "lo intangible", a la actividad de la crítica como "conexión entre el emisor y el receptor" y a la escritura, por lo tanto, como búsqueda de "la verdad tal como fue concebida por el artistaemisor" (54-56).

Sin embargo, nos gustaría concentrarnos en uno de los ensayos de La danza y la palabra por ser acaso el que mejor representa la pervivencia de lo que Schaeffer llama "teoría especulativa del Arte". El ensayo se titula "Enunciación de lo que somos" y su autor es Leyson Ponce. La formulación del tema adelanta, en efecto, un modo de pensamiento en el que se considera que, en lo que sea que esté materializada la enunciación de la danza, puede efectivamente decir algo sobre lo que somos. La cita de Valéry que Ponce elige como epígrafe lo anticipa: "La danza es un exceso de vida" (43).

Desde el comienzo, Ponce advierte que su indagación versará acerca de la esencia de la danza y su condición de ser una "manifestación de la expresión intangible" (43) En otras palabras, la materialidad del lenguaje de movimiento no es lo fundamental, sino aquello que no se puede tocar que estaría detrás o más allá de lo que sucede en escena. Además, asume directamente que la danza es "lenguaje de una intrincada dimensión de las expresiones del alma en movimiento" (43). Ponce propone que la danza trabaja en "lo sobrante de la vida" y de ese modo puede trascender la "vida limitante", esto es, la vida ordinaria, creando un "sobre tiempo". Así, retomando el dualismo metafísico al que hace referencia Schaeffer, el abordaje postula dos "vidas" o dos espacios de acceso: la vida común y la vida que está más allá, a la cual solo la danza puede abrir camino.

Inmediatamente, Ponce afirma que eso que sobra, ese "resto" que es la danza, la danza verdadera, constituye "la expresión más pura del movimiento". Se observa aquí lo que Schaeffer refiere en relación con el "ideal artístico": como no se considera bajo ningún concepto el ámbito de la recepción, la tesis comporta el problema de cómo (a partir de qué formas, de qué calidades de movimiento, en suma, de qué tipo de materialidad) podría encarnarse esa expresión pura. Dicho de otra manera, encierra una concepción que, en el fondo, es más prescriptiva que analítica: la danza tiene ni más ni menos que el objetivo de descubrir las "formas vitales del inconsciente como códigos de un lenguaje del alma" (44). Y como el alma es la realidad verdadera del hombre - 
la Vida- ese más allá de la vida no es la muerte, como podría pensarse: "La danza entonces es vida en la vida" (44).

Ponce le otorga así a la danza un rol tan primordial en la sociedad que difícilmente pueda cumplir y, cuando la aparta de todo lo relacionado con lo consciente ("no acepta el habla de la conciencia"), retoma una oposición heredada también del romanticismo: mientras para los románticos el arte debía equilibrar el superdesarrollo de lo "racional" frente a lo sensible, de lo que ahora se trata es de enfrentar los "tiempos de contraste y de esquizofrenia de la información" (44). La danza estaría llamada a recuperar una supuesta pureza del ser humano ante la irrupción de la globalización y la omnipresencia de los medios de comunicación.

Ponce ve, primeramente, la relación entre danza y escritura como un límite, como un espacio de "roce" y de encuentro en donde la palabra puede convertirse en un modo de generar la permanencia en el movimiento. Más adelante, afirma que muchos pensadores han querido dialogar con la danza desde la palabra y ratifica que lo que se diga, sin embargo, únicamente puede constituir un acercamiento tangencial, que no hace justicia al lenguaje de movimiento consistente en "la expresión de lo indecible": "nombrar la danza tiene el pecado de limitar la trascendencia de su configuración" (44). Este modo de entender la relación danza/palabra insiste en diferenciar entre la dimensión de la producción del arte (de su sentido, de su ontología y hasta de su metafísica) como actividad creadora y la de la (o las) instancia(s) de reconocimiento, como intentos (siempre fallidos) de desciframiento de la esencia del arte. Para Ponce, el desciframiento consiste en la recuperación del exceso de la danza, pero al considerarlo trascendente, fuera de lo consciente y expresión del alma, el mismo resulta inefable.
De acuerdo con Ponce, la obra de danza está íntimamente relacionada con el inconsciente del creador. Incluso llega a comparar el contenido de lo que intenta comunicar con la esencia de Dios. Si esto es así, no resulta sorpresivo que se considere el movimiento que lo representa como indecible o innombrable, haciendo hincapié en la idea de que la palabra solo podría "parafrasear" la danza a partir de sus propios ritmos y "acepciones" (44). Se observa claramente cómo la escritura es pensada como un desciframiento o una decodificación, aunque destinadas a fracasar, de esa supuesta comunicación que el movimiento lleva a cabo. El restablecimiento del equilibrio humano esencial queda a cargo del coreógrafo, como potador del poder de transmisión de ese inconsciente compartido, negando que el ordenamiento social de los textos y sus diferentes y posibles reconocimientos se base, en cambio, en un proceso interdiscursivo común. El espacio de expectación no tiene lugar en este planteo, salvo como un destinatario aparentemente pasivo: el coreógrafo "nos otorga un sistema intrincado de resoluciones que conforman un orden escénico estructurado en el pensamiento del convocado" (45).

Ponce abiertamente expresa que el gesto, no cualquiera sino el que se implica en la danza es "una apertura al misticismo": al intentar transmitir lo indecible, no con palabras sino mediante movimientos, la danza revela eso que no se puede nombrar: es la "codificación del decir en el vacío" (45). En esta línea de pensamiento, lo real es lo que no puede ser conocido por el sujeto a partir de la racionalidad y la danza, por consiguiente, posee límites que son "infranqueables". Ni el espectador en general a partir de sus capacidades racionales, ni el crítico a través de su escritura, pueden acceder realmente a sus encantos; solo alcanzan a acercarse tangencialmente. El único modo de arribar a la verdad de la obra es de manera inconsciente a través de una intuición. 


\section{DANZA, ESCRITURA Y EXPERIENCIA ESTÉTICA}

El ensayo de Ponce muestra de qué manera aún hoy, como advierte Schaeffer, persiste en la teoría de la danza un pensamiento de raíces románticas. La realidad cotidiana, percibida desde un punto de vista desencantado (no ya como consecuencia de una crisis religiosa o filosófica, sino a través de otras figuras de la desilusión, como el avance de los procesos globales económicos, políticos y de la información), con frecuencia lleva a ver en la danza un modo de llegar a esa otra cosa que, por contraposición, se considera más genuina. Así, se postula un contenido esencial que la danza debe expresar adaptando su forma "externa", sus tipos y calidades de movimientos, no así su forma "interna", esto es, el hecho de ser efímera y supuestamente no racional e "intangible”. La escritura, por lo tanto, si aún guarda algún sentido, debe convertirse en un desciframiento o búsqueda de esa verdad que revelaría la obra. La crítica, en consecuencia, queda relegada a "empujar" al espectador, a acercarlo de algún modo hacia esa intuición inconsciente necesaria para llegar a la realidad verdadera a través de la observación del movimiento.

Es cierto que el arte del movimiento es un lenguaje efímero, y en este muy estrecho sentido podríamos acordar con la idea de que es intangible. Pero de ningún modo esto significa que la danza no tenga una materialidad mediante la cual genera sentido: tanto los espectadores, como los críticos pueden penetrar en el entramado de múltiples significaciones que provoca el encuentro cuerpocuerpo. Se hace necesario, por lo tanto, repensar este modo de entender la danza y, particularmente, su relación con la palabra. En primer lugar, es necesario bajar la danza, y el arte en general, del pedestal en el que la colocó el romanticismo (y que intuimos también arrastra de su condición de ritual en esta y otras socie- dades) como actividad que tiene el poder de restituir una parte perdida u olvidada del ser humano, supuestamente no racional, sensible, relacionada con lo inconsciente, que se vería disminuida por el desarrollo de la ciencia o el avasallamiento de los medios masivos de comunicación o la globalización imperante.

En segundo lugar, apartarse de esta lógica también colaboraría en dejar de pensar la escritura acerca de la danza (crítica o teórica, la actividad metadiscursiva en general) como un intento de desciframiento o esclarecimiento de una obra, sino como un lenguaje que en sí mismo también es creativo: en lenguaje que se enred-a (de "hacerse red con") en la trama interdiscursiva, como un discurso de reconocimiento de esa obra, que es, a su vez, condición de producción de otros discursos y que esta interrelación es, además, el modo en que ambas actividades discursivas se hacen efectivamente significativas (véase Verón, 2004). Si se piensa la escritura de este modo, se le saca el terrible peso de tener que encontrar una "verdad" o un "contenido correcto" en la obra y abre, y multiplica, creemos, las posibilidades analíticas que emergen cuando se piensa la danza (y el arte) como formando parte de esa red de relaciones discursivas.

La pregunta que parece querer responderse en La danza y la palabra es: ¿qué es la danza? Pero desde los desarrollos de Nelson Goodman (1978) sabemos que esta pregunta por la esencia es un interrogante que clausura el análisis y lo sentencia a una única y absoluta respuesta posible. La danza nunca es algo. Ningún arte es, aun menos la danza (podríamos aventurarnos a decir) que, por definición, siempre está siendo; es decir, es algo en permanente movimiento $y$, por lo tanto, en permanente cambio. Lo interesante no es preguntarse qué es la danza, sino reflexionar 
acerca de cómo y en qué circunstancias es, cuál es la relación entre sus procesos de producción y de reconocimiento.

La relación entre danza y palabra pareciera ser mucho más densa y fructífera si se la piensa como una relación entre dos discursos con lenguajes y soportes diferentes, en la cual, en todo caso, el segundo, la escritura, toma como objeto a la primera, pero no para ayudar a entender qué quiso decir el "artista-emisor" o cuál es la "verdad" que intentó revelar en su obra. Lo que se trata de ver es que justamente es en esa relación que tanto la danza como la palabra hacen sentido.

A este respecto, resulta relevante retomar una idea que instala Pérez-Wilke en La danza y la palabra. La autora establece que hay una relación directa entre lo inefable y la capacidad de la danza (de la "acción danzaria, ya sea escénica o colectiva") de develar eso que no se puede decir. Gracias a que la danza es inefable (es decir, que no está asociada con lo racional -la escritura, en este caso-) es que puede "hablar" de lo imposible, de lo "inhumano", en el sentido de eso que el humano no puede conocer racionalmente, o como lo refería Ponce: "lo sobrante de la vida" (Paolillo 2005: 43). De hecho, Pérez-Wilke se refiere a este proceso como la "transfiguración de lo humano" (36). La tesis subyacente es que lo racional se puede decir, pero lo otro (lo emocional, lo sensible, lo artístico) es inexpresable en estos términos. La danza es capaz de expresar el ser, lo verdadero del hombre, porque esa esencia no es un "contenido" racional y el lenguaje del movimiento es, en su "éxtasis", una fuerza oculta inhumana, en tanto todo lo humano (cotidiano) parece estar en duda por el desencantamiento con la sociedad actual.
Para lograr esta transfiguración, Pérez-Wilke vincula la danza con la muerte. Como acerca lo humano a lo inhumano, y en ese hacer es "revolucionaria", cuestionadora de los órdenes establecidos, se dice que para bailar (y hacer arte en general) se debe estar dispuesto a perecer: "la naturaleza misma de lo creativo exige esta disposición a perecer" (37). De este modo, la experiencia estética se vuelve una especie de éxtasis místico a través del cual puede revelarse algo de una supuesta realidad verdadera, en vez de concentrarse en la expectación como una "enunciación encarnada", según la expresión de Héctor Ponce de la Fuente (2012), que se acaba allí donde termina la experiencia misma.

La propuesta que Sonia Sanoja elaboró para su curso -y que fue el motor de los ensayos publicados en La danza y la palabra- fue atravesar un proceso de creación de danza y plasmar luego esas experiencias en "personales discursos literarios" que plantearan la relación de lo que los organizadores llamaron, separadamente, "la danza como cuerpo" y "la danza como verbo" (Paolillo 2005: 5-6). En este sentido, se puede sostener también que este pensamiento sobre la danza no repercute solo sobre los metadiscursos del lenguaje, sino también sobre los propios procesos de producción, generando una línea de trabajo que obtura cualquier otro tipo de práctica que no sea un intento de manifestar las expresiones del alma, con lo que eso sea que implique para cada coreógrafo. Trabajar para expresar el alma humana no es lo mismo ni tiene la misma carga que trabajar para contar una historia o trabajar pensando la danza como una actividad más dentro de la red de significación social.

Como mencionamos más arriba, la particular fugacidad que posee el lenguaje de la danza la ubica en un lugar privilegiado para que entren en juego las tesis que hacen de su experiencia estética 
una vivencia extática y de sus metadiscursos empresas casi imposibles. Sin embargo, aún si ese espejismo del que habla Schaeffer no se relaciona directamente con una práctica mística, puede observarse igualmente la influencia de la "teoría especulativa del Arte" no ya en la búsqueda de un encuentro con lo real o lo verdadero sino en la determinación de una manera de ser y de hacer (correcta) de la danza.

\section{OTRAS PERSPECTIVAS TEÓRICAS}

En relación con lo que estamos discutiendo, resulta pertinente traer a colación, aunque más no sea brevemente, un debate ocurrido en 1982, a partir de dos artículos publicados en el mismo número del Dance Research Journal. Esta discusión refleja una de las diferencias más relevantes con respecto a los temas que venimos tratando: el de las posturas teóricas que buscan una manera de ser de la danza en general (de qué se compone, cuáles son sus elementos básicos, qué movimientos son "de danza" y cuáles no, cómo son o deberían ser sus formas, etc.) y, en función de ello la necesidad de una gramática apropiada para la construcción de una obra, frente a planteos que, en cambio, ponen el acento en los elementos contextuales y en las relaciones con el espectador.

En defensa de la primera postura, Monroe Beardsley (1982: 3136) se propone encontrar cuáles son los tipos de acciones que conforman la danza. Con la ayuda de algunas categorías de la filosofía de la acción, sostiene que las "acciones" (movings) de la danza no son meros "movimientos corporales" (bodily motions), sino movimientos corporales que sufren determinadas transformaciones y que, de esta manera, toman el carácter de "acciones de danza" (dance movings). El problema consiguiente es el de encontrar cuáles son tales transformaciones y cómo pueden observarse. Beardsley enumera entonces una serie de características que los movimientos deben tener para ser danza. Condiciones del hacer que, aunque parten de la observación, no tardarán en convertirse en criterios de la buena danza, incluso insiste en la búsqueda de una "adecuada caracterización de la danza como un arte".

Para contarse dentro del mundo del arte de la danza, agrega Beardsley, los movimientos deben ser "expresivos" (es decir, deben estar intensificados de alguna manera), pero esa "amplificación de energía" debe ser una cualidad volitiva del movimiento, el cual debe representar de alguna manera acciones de otro tipo (el autor sugiere, especialmente para la danza, la suggestings, que es un tipo de representación de carácter bastante abstracto que sugiere la acción original de una manera lavada o combinada con otras). No obstante, Beardsley reconoce que existe también una danza que utiliza tipos de movimientos de un grado tan abstracto en donde la representación desaparece. Destaca, además, la categoría de lo no-práctico (de acciones que no poseen un objetivo práctico a cumplir más que el de otorgar placer) como elemento fundamental. Por esta razón, su sugerencia final reside en que los movimientos o conjuntos de movimientos pueden convertirse en acciones de danza si no persiguen ningún fin práctico y solo si existe en ellos un "desborde de expresividad".

Para Noël Carroll y Sally Banes (1982: 37-41), representantes de la segunda postura, este "desborde de expresividad" de los movimientos no constituye una condición necesaria ni suficiente para hablar de danza. Arguyen que el desborde de expresividad (en el sentido de realizar movimientos intensificados o rítmicos que no aportan directamente al fin práctico al que está orientada 
la acción) se puede producir en espacios que se relacionan con el trabajo sin que eso constituya una danza. Por otro lado, afirman que existen muchas obras que no poseen ese desborde de expresividad, es decir, que consisten simplemente en la realización de una acción cotidiana sobre el escenario, sin ningún tipo de amplificación o expansión, y que son danza. Carroll y Banes traen a colación el ejemplo de una obra de Ivonne Rainer, Room Service (1963), que despliega justamente un movimiento con un fin directamente práctico: cargar un colchón de un lugar al otro del escenario.

Esta acción no está representada, sino que es la acción misma y también es danza. Que sea danza depende de otras variables; por ejemplo, del acto del coreógrafo de poner sobre el escenario determinados movimientos, lo cual los recontextualiza como expresión artística, y, por otro lado, porque forman parte de una historia del arte (y de la danza) que le otorga un marco de legitimidad, en este caso, el marco del arte contemporáneo al compartir algunas preocupaciones como el anti-ilusionismo, el arte desmitificado, negación de la representación, etc. Lo fundamental para resaltar aquí es que esta postura, a diferencia, de la de Beardsley, propone criterios que se alejan de la delimitación de la danza a partir de la observación únicamente de las características intrínsecas del objeto. Así, Carroll y Banes resaltan la importancia del contexto, tanto espectatorial como histórico, y del acto del coreógrafo de poner sobre el escenario, por ejemplo, movimientos considerados ordinarios o prácticos.

Este contraste permite observar cómo los defensores de la búsqueda de características intrínsecas sentencian el arte de la danza a un marco de acción acotado porque, al buscar cualidades que el objeto debe poseer para ser artístico, limitan el margen de acción del coreógrafo a un determinado tipo de movimientos o acciones y ponen en relación directa la experiencia estética con algún tipo de evaluación o juicio de valor. Las cualidades que en algún momento pudieron ser observadas efectivamente en las obras, se convierten en parámetros de evaluación; como decíamos previamente, una gramática de producción se convierte en regla de creación y en criterio evaluativo externo. Los autores que consideran la danza desde este punto de vista tienden a convertir la experiencia estética en un espacio de legislación y a elaborar sus metadiscursos a partir de un criterio fuertemente evaluativo y a marcar límites del arte en general y del lenguaje en particular y se pierden en discusiones filosóficas interminables sobre cómo debe ser un movimiento o una obra para ser danza.

En cambio, una concepción que piensa el hecho artístico como una relación e incluye el marco histórico en el que una obra se produce tiende a generar metadiscursos para los cuales es importante la contextualización del momento en que el trabajo se produce. Así, en vez de estar esperando que una creación deba tener determinados tipos de movimientos, un texto teórico o crítico puede alejarse del anclaje evaluativo (aunque puede seguir teniéndolo, por supuesto) y puede acercarse a una mirada más descriptiva y perceptual de la obra.

Pero lo más importante de esta mirada es que logra mantenerse mucho más abierta a los cambios que pueden llegar a producirse durante el desarrollo histórico de lenguaje artístico. La experiencia estética puede, de este modo, poner su acento no tanto en una actividad extática o valorativa, sino más bien en el disfrute perceptual y conceptual de una obra de danza. Posturas similares pueden encontrarse en la propia Banes (1994), quien plantea que la manera de escribir sobre las obras va modificándose en 
parte por los cambios en los desarrollos poéticos de la danza, así como en Ann Daly (2002), quien propone que la danza está compuesta tanto por movimientos como por las palabras que la rodean y resalta la importancia de la experiencia subjetiva y corporal en la observación de la obra y o en la crítica, como Deborah Jowitt, Marcia Siegel y Jill Johnston, entre otros, que, bajo la influencia del ensayo de Susan Sontag "Contra la interpretación" (1966), famoso en el ambiente de la danza de los años sesenta, bregaban por un discurso sobre el arte que no se basara en la dilucidación del contenido de la obra, sino en la descripción sensitiva de sus elementos.

En nuestro caso, y para terminar, consideramos que a la postura de Carroll y de Banes deben sumarse los discursos de reconocimiento. Es justamente la posibilidad de acceder a estos contrastes de lecturas (en este caso teóricos, pero también críticos) sobre una misma obra o sobre la danza en general que hacen que la danza misma pueda construir sentido para cada espectador y, de manera más general, dentro de una historia del arte. Así, al contrario de lo que dijera Leyson Ponce, nombrar la danza no tiene "el pecado de limitar la trascendencia de su configuración", sino la bondad de multiplicarla y expandir sus fronteras.

\section{REFERENCIAS}

BANES, Sally (1994), Writing Dancing in the Age of Postmodernism (Hanover: University Press of New England).

BANES, Sally \& CARRolL, Noël (1982), "Working and Dancing: A Response to Monroe Beardsley's 'What Is Going on in a Dance?'”, Dance Research Journal, 15/1: 37-41.

BeardSley, Monroe C. (1982), "What Is Going on in a Dance?", Dance Research Journal, 15/1: 31-36.
DALY, Ann (2002), Critical Gestures: Writings on Dance and Culture (Middletown, CT: Weslwyan University Press).

DALMASSO, María Teresa (comp.) (2012), Semiótica e interdisciplina: perspectivas de investigaciones en curso (Córdoba: Centro de Estudios Avanzados).

Goodman, Nelson (1978), "When is Art?", en Ways of Worldmaking (Indianápolis: Hacket Publishing Company): 57-70.

PAolillo, Carlos (coord.) (2005), La danza y la palabra (Caracas: Instituto Universitario de Danza, Asociación Civil Publicaciones La Danza).

PonCE DE LA Fuente, Héctor (2012), "Cuerpo y narratividad", en Dalmasso (2012: 15-23).

SCHAEFFER, Jean Marie (2012), Arte, objetos, ficción, cuerpo. Cuatro ensayos sobre estética, prólogo, selección y trad. de Ricardo Ibarlucía (Buenos Aires: Biblos, col. Pasajes).

VERóN, Eliseo [1993] (2004), La semiosis social, trad. de Emilio Lloveras (México: Gedisa). 